\title{
Acolhimento Familiar: Uma Alternativa de Proteção para Crianças e Adolescentes
}

\author{
Family Foster Care: A Protective Alternative for Children and Adolescents
}

\author{
Nina Rosa do Amaral Costa* \& Maria Clotilde Rossetti-Ferreira \\ Universidade de São Paulo
}

\begin{abstract}
Resumo
$\mathrm{O}$ acolhimento de crianças e adolescentes que vivenciam violação de direitos tem sido discutido no âmbito do desenvolvimento de políticas públicas e no meio acadêmico. Tais discussões visam elaborar diretrizes que garantam o direito à convivência familiar e comunitária e evidenciam um campo em reordenamento. Este artigo contextualiza o acolhimento familiar no cenário nacional, considerando-o como uma medida de proteção possível para crianças e adolescentes em situação de vulnerabilidade. Discute-se também o reflexo de algumas perspectivas teóricas que abordam as relações de vínculo afetivo em situações de acolhimento. Argumenta-se que ao fomentar uma nova cultura de acolhimento são necessárias mudanças nas concepções de infância e juventude, nas significações de vinculação afetiva e nas políticas de assistência à infância e juventude.

Palavras-chave: Acolhimento familiar; família; criança; adolescente; medidas de proteção.
\end{abstract}

\begin{abstract}
Foster care of children and adolescents who have had their rights violated is being discussed both in the scientific literature and in agencies involved in the development of public policies. Such discussions, which aim to define some guidelines to guarantee the right to family and community inclusion, expose a field under change. This paper focuses on foster care in the Brazilian context and presents it as one of the possible alternatives for children and adolescents in risk situations. The (mis)leading influences of some theoretical perspectives that deal with affective bonds in foster care are also discussed. It is argued that a new foster culture requires changes in the conceptions of infancy and youth, in the meanings of affectionate bonds, and in welfare policies for children and adolescents.

Keywords: Foster care; family; child; adolescent; protective measures.
\end{abstract}

O tema acolhimento de crianças e adolescentes em situações de vulnerabilidade social vem ganhando espaços importantes de discussão tanto no âmbito do desenvolvimento de políticas públicas, quanto no meio científico-acadêmico e jurídico. Tais discussões estão presentes na agenda nacional ao se buscar traçar diretrizes que garantam o direito à convivência familiar e comunitária, e que favoreçam a desinstitucionalização de crianças e adolescentes.

Nesse sentido, o acolhimento de crianças e adolescentes em situação de vulnerabilidade é um campo em plena transformação e reordenamento. Transformações que se encontram tanto no campo das políticas macro-sociais, como das práticas cotidianas desenvolvidas pelas equipes multiprofissionais de técnicos de secretarias municipais, de abrigos ou do Poder Judiciário, ao atuarem dentro do Sistema de Garantia de Direitos de seus municípios. Por isso mesmo,

*Endereço para correspondência: Universidade de São Paulo, Faculdade de Filosofia, Ciências e Letras de Ribeirão Preto, Depto. de Psicologia e Educação (CINDEDI), Av. Bandeirantes, 3900, Monte Alegre, Ribeirão Preto, SP, CEP 14040-901. E-mail: ninarosa@usp.br

Agradecimentos à Fundação de Amparo à Pesquisa do Estado de São Paulo (FAPESP) e Conselho Nacional de Desenvolvimento Científico e Tecnológico (CNPq). faz-se necessária uma ampla discussão do tema, o que estimula a produção de conhecimento em diferentes áreas de estudo (Serviço Social, Psicologia, Direito, dentre outras) sobre os diversos aspectos envolvidos no acolhimento familiar.

Este artigo tem o objetivo de contextualizar o acolhimento familiar no âmbito das discussões e normativas nacionais sobre o assunto e de propor reflexão sobre o mesmo, como medida de proteção às crianças e adolescentes em situação de vulnerabilidade. Para tanto, foram destacados três pontos em sua discussão: (a) o acolhimento familiar no cenário nacional; (b) o acolhimento familiar como alternativa de proteção e (c) o reflexo de algumas perspectivas teóricas que norteiam compreensões sobre vinculação afetiva em situações de acolhimento.

\section{O Acolhimento Familiar no Cenário Nacional}

O Levantamento Nacional de Abrigos para Crianças e Adolescentes (Instituto de Pesquisa Econômica Aplicada [IPEA], 2003; Silva, 2004) realizado pelo IPEA junto às instituições cadastradas na Rede de Serviços de Ação Continuada (SAC) do Ministério do Desenvolvimento Social, estimou que em torno de 80.000 crianças e adolescentes 
estão vivendo em instituições de abrigo no Brasil. Entretanto, a maioria das crianças e adolescentes dos abrigos investigados tem famílias $(86,7 \%)$, sendo que foram afastados de suas famílias por situações de negligência, abandono ou violência e possuem um perfil considerado distante do desejado para adoção (58,5\% meninos, $63 \%$ afro-descendentes e $61,3 \%$ com idade entre 7 e 15 anos). Muitos passam longos períodos nos abrigos, existindo aqueles que passam toda a infância e adolescência. São provenientes de famílias pauperizadas, que enfrentam várias dificuldades quanto à sua manutenção e subsistência (Silva, 2004).

Com o intuito de enfrentamento e transformação dessa realidade, o Ministério do Desenvolvimento Social (MDS), a Secretaria Especial dos Direitos Humanos (SEDH), o Conselho Nacional dos Direitos da Criança e do Adolescente (CONANDA), o Conselho Nacional de Assistência Social (CNAS), entre outros, vêm protagonizando discussões para implantar diretrizes e ações de fortalecimento do paradigma da proteção integral da criança e do adolescente, garantindo a sua condição de sujeito de direitos e de pessoa em desenvolvimento. Essas ações buscam promover e garantir seus vínculos familiares e comunitários, adequando-se ao que é preconizado pelo Estatuto da Criança e do Adolescente (ECA, 1990) e pela Convenção sobre os Direitos da Criança (Organização das Nações Unidas [ONU], 1989).

Tal processo acontece simultaneamente a discussões internacionais lideradas pelo Comitê dos Direitos da Criança da ONU, sobre a necessidade de serem aprimorados os mecanismos de proteção integral dos direitos da criança privada dos cuidados parentais (em especial o direito à convivência familiar e comunitária). Pretende-se com isso a elaboração de nova normativa internacional sobre o assunto. O Brasil empenha-se no fortalecimento dessas discussões, tendo sediado em 2006 a Reunião Intergovernamental de Especialistas para Revisão do Esboço das Diretrizes Internacionais sobre Proteção e Cuidados Alternativos de Crianças Privadas de Cuidados Parentais, apoiada pelo MDS, Fundo das Nações Unidas para a Infância (UNICEF) e Comitê dos Direitos da Criança da ONU.

Além disso, o governo brasileiro, em consonância com esse movimento de reordenamento e de construção de normativas, elaborou e aprovou em dezembro de 2006 um plano que traça diretrizes nacionais para as medidas de apoio sócio-familiar, de acolhimento familiar e institucional e de adoção: o Plano Nacional de Promoção, Proteção e Defesa do Direito de Crianças e Adolescentes à Convivência Familiar e Comunitária (MDS \& SEDH, 2006). Ao longo deste artigo, referimos a esse plano como Plano Nacional. Ele busca incorporar na sua plenitude a "doutrina da proteção integral", tendo mobilizado no processo de sua construção discussões sobre o acolhimento familiar entre os órgãos de classe, entre grupos de pesquisa e de intervenção ligados à infância e juventude, entre magistrados, promotores da infância e juventude, além de outros atores que compõem o Sistema de Garantia de Direitos.

Fica evidente o empenho para o reordenamento da política nacional de assistência com o foco na família, valori- zada como o espaço ideal de convivência para a criança e o adolescente.

Este Plano constitui um marco nas políticas públicas no Brasil, ao romper com a cultura da institucionalização de crianças e adolescentes e ao fortalecer o paradigma da proteção integral e da preservação dos vínculos familiares e comunitários preconizados pelo Estatuto da Criança e do Adolescente. A manutenção dos vínculos familiares e comunitários - fundamentais para a estruturação das crianças e adolescentes como sujeitos e cidadãos - está diretamente relacionada ao investimento nas políticas públicas de atenção à família (MDS \& SEDH, 2006, p. 14).

Dessa forma, o acolhimento familiar, que já aparecia na Política Nacional de Assistência Social (MDS, 2004), relacionado como um programa a ser implantado dentro dos serviços de Proteção Social Especial de Alta Complexidade, passa a ser reconhecido como parte integrante das políticas sociais do país. Fica reconhecido como estratégia que objetiva o acolhimento temporário de crianças e adolescentes, visando sua reintegração familiar e buscando evitar a institucionalização. Ou seja, o acolhimento familiar é compreendido como uma medida protetiva, a qual possibilita à criança e ao adolescente em vulnerabilidade e afastado de sua família de origem ser colocado sob a guarda de uma outra família. Essa família é previamente selecionada, cadastrada e vinculada a um programa. Ela acolherá a criança ou adolescente por um período. Paralelamente ao acolhimento, é necessário trabalhar as causas do afastamento junto à família de origem de maneira a contribuir, efetivamente, para uma reintegração familiar como preconizado pelo ECA (1990). "As estratégias, objetivos e diretrizes deste Plano estão fundamentados primordialmente na prevenção ao rompimento dos vínculos familiares, na qualificação do atendimento dos serviços de acolhimento e no investimento para o retorno ao convívio com a família de origem" (MDS \& SEDH, 2006, p. 14).

O acolhimento familiar como prática social não é algo novo no Brasil, tendo acontecido ao longo da história de modo informal através das práticas de circulação de crianças, por famílias que acolheram os chamados "filhos de criação ou afilhados" (Fonseca, 2004; Franco, 2000; Sarti, 1996). Contudo, somente agora ele é proposto como um programa oficial, que compõe uma política pública de atendimento à criança e ao adolescente privado dos cuidados parentais, com suporte legal e acompanhamento técnico. Nesse sen-tido, constitui uma experiência nova na história do país. Daí a necessidade de pesquisas que possam acompanhar tanto as experiências de programas já existentes a partir de iniciativas locais, como a implantação da medida a nível nacional através da criação dos programas municipais. Por exemplo, Cabral (2004), Fávero (1995) e Uriarte Bálsamo (2005) relatam iniciativas históricas de acolhimento familiar no Brasil. Essas investigações devem abordar diferentes aspectos do acolhimento familiar, focando os seus distintos protagonistas (família acolhedora, equipe dos programas, criança e adolescente acolhidos, família de 
origem), como também as significações que circulam em seu contexto quanto às questões relacionadas a manutenção e rompimento de vínculos afetivos, reintegração familiar, acolhimento em famílias, dentre outras questões envolvidas nessa prática de acolhimento.

\section{O Acolhimento Familiar como Alternativa de Proteção}

O acolhimento familiar foi instituído como política assistencial em diferentes países em resposta a condições históricas específicas, tais como situações de guerra e pós-guerra, mudanças de paradigmas em relação à infância e ao status da família, crises econômicas, avaliações sobre os efeitos prejudiciais da institucionalização de crianças (Luna, 2004). Nos EUA e Canadá, por exemplo, o acolhimento familiar foi implementado, ainda no século XIX. Posteriormente, trabalhos como os de Bowlby, Spitz e Winnicott fundamentaram melhor a construção dessa medida de proteção, e já há alguns anos as políticas públicas desses países preconizam que todas as crianças e adolescentes separados dos seus pais sejam acolhidos em uma outra família (Brasil, 2004; George \& Van Oudenhoven, 2003). Vale ressaltar que o acolhimento familiar na Inglaterra e em Israel data do período pós Segunda Guerra e que nos Estados Unidos já havia indicação de que seria melhor acolher crianças e adolescentes em famílias substitutas do que em instituições, desde o $1^{\circ}$ Congresso Sobre a Infância, ocorrido em 1909 (Luna, 2004).

Atualmente, na Inglaterra, o foster care caracteriza-se pela transferência temporária ou permanente dos deveres e direitos parentais dos pais biológicos para um outro adulto com quem a criança ou adolescente, em geral, não tem relações consangüíneas. Para isso, as autoridades locais devem traçar um plano de intervenção que justifique essa transferência como fundamental para o bem-estar da criança ou adolescente. A colocação em uma família acolhedora visa garantir os cuidados básicos (alimentação e suporte ao desenvolvimento físico, emocional e educacional), mas não altera a identidade da criança ou de seus pais biológicos, nem substitui os direitos e obrigações que envolvem tal condição. Nesse sentido, o acolhimento familiar é um processo de criação e não uma redefinição jurídica do status familiar da criança. As famílias biológicas podem colaborar com as famílias acolhedoras e ambas são acompanhadas e supervisionadas por profissionais da área psicossocial (Cabral, 2004; George \& Van Oudenhoven, 2003).

Outros países europeus, como França, Itália e Espanha, implementaram o acolhimento familiar a partir de meados da década de 70 , em resposta à necessidade de reordenamento das políticas de atenção à infância e juventude em situação de vulnerabilidade. Na Espanha, conforme Fernández, Álvarez e Bravo (2003) e Palacios e Amorós (2006) relatam, o acolhimento familiar e a adoção mudaram como reflexo das modificações legislativas de 1987 e 1996, que passaram a priorizar "o melhor interesse da criança." A nova legislação estabeleceu que esses interesses devem ser providos por uma família e não por uma instituição, e que as decisões sobre medidas de proteção à criança precisariam ser tomadas por uma equipe de profissionais habilitados (psicólogos e assistentes sociais). Assim, as mudanças legislativas e sociais formaram um panorama que favoreceu novas práticas de acolhimento e, conseqüentemente, novas concepções de família acolhedora. Isso porque não existia na Espanha uma cultura de acolhimento, sendo o acolhimento familiar, então, um recurso pouco conhecido pela sociedade e pelos próprios administradores públicos. Ele era restrito à modalidade de acolhimento pré-adotivo (onde não é realizado um trabalho com a família de origem) e pouco atendia às necessidades das crianças que precisavam do Sistema de Proteção (Amorós \& Palacios, 2004; Amorós \& Peláez, 2004).

Essa situação mudou a partir da década de 90 , sendo que atualmente o acolhimento familiar naquele país subdivide-se em diferentes modalidades e conta com um banco de famílias cadastradas, selecionadas e formadas para acolher. Além disso, ele busca absorver toda a demanda de crianças e adolescentes em vulnerabilidade que necessitam de acolhimento, embora ainda existam pequenas instituições de abrigamento (Amorós, Palacios, Fuentes, \& León, 2003). Hoje, na Espanha, o acolhimento familiar constitui uma alternativa de proteção mais utilizada que o acolhimento institucional (Del Valle \& Arteaga, 2003).

No Brasil, de modo semelhante ao que acontecia anteriormente na Espanha, o abrigamento em instituições constituiu-se historicamente na modalidade de proteção mais utilizada para crianças retiradas de sua família por negligência, violência, abandono ou orfandade (Baptista, 2006; Fonseca, 1995; Justo, 1997; Rizzini \& Rizzini, 2004). Desde a criação das Rodas de Expostos para os enjeitados, as políticas de assistência às crianças e adolescentes em vulnerabilidade priorizaram o internamento em instituições, com pouco ou nenhum convívio comunitário e social e com favorecimento do rompimento dos vínculos familiares (Rizzini, 1993). É importante pontuar que esse tipo de assistência foi criado para os desvalidos, filhos de famílias com poucas condições sócio-econômicas, pauperizadas, que eram vistos como "carentes", possíveis "delinqüentes" ou "vadios" e, portanto, precisavam ser educados e controlados, enquanto suas famílias eram consideradas incompetentes para cuidar e educar.

Fonseca (2004) afirma que com a insuficiência de políticas públicas adequadas, o abrigo ainda funciona como um "colégio interno" para crianças pobres, quando suas mães vivenciam o esgotamento dos recursos financeiros e de sua rede social de apoio. França (2006) ratifica esse argumento ao descrever a experiência do projeto de Famílias Acolhedoras de Diadema (SP), em que várias mães ou parentes dos acolhidos diziam preferir que suas crianças tivessem sido encaminhadas para um abrigo a que fossem encaminhadas para famílias acolhedoras. Acreditavam que na instituição não corriam o risco de perder a criança, pois significavam o abrigo como um local onde ela é cuidada, tem acesso ao estudo e tem maior estabilidade, enquanto as mães e/ou familiares tentam conseguir sua sobrevivência. "As mães acreditavam que, após resolverem seus 
problemas, teriam seus filhos de volta naturalmente, desconhecendo que estavam abrindo mão da guarda, seja em favor do abrigo, seja em favor da família acolhedora" (França, 2006, p. 76).

Conforme se pode observar, implantar uma nova proposta de acolhimento para crianças e adolescentes cujos direitos são violados, que seja de qualidade e mais eficaz que a antiga institucionalização, exige tempo e mudanças. Mudanças de ordem legal, de práticas institucionais, de paradigmas de família, de concepções de criança e adolescência, de práticas e políticas sociais.

Do ponto vista legal, já ocorreram transformações que possibilitam ao acolhimento familiar ancorar-se em leis e normativas. A Constituição da República Federativa do Brasil (1988), o ECA (1990), a Lei Orgânica da Assistência Social ([LOAS], 1993), somados à Política Nacional de Assistência Social (MDS, 2004) e ao Plano Nacional (MDS \& SEDH, 2006), deram base e constituíram o marco legal para a argumentação, justificativa e inclusão do acolhimento familiar como uma política pública nacional. Vale destacar que ocorreram iniciativas do Poder Judiciário e municipais antes da elaboração desses dois últimos documentos nacionais que preconizam o acolhimento familiar (vide a experiência dos projetos de Acolhimento Familiar do Estado de São Paulo), mas nesses casos tratase de políticas locais de assistência social.

Ao afirmar que "a família é a base da sociedade" (art. 226 e 227) e que a criança ou adolescente tem direito à "convivência familiar e comunitária," a Constituição Federal (1988) reforça o papel da família na vida da criança e do adolescente como elemento fundamental dentro do processo de proteção integral e como parceira do Estado nessa proteção. Desse modo, quando esgotados os recursos ou possibilidades da permanência da criança na família de origem, dispõe a lei que os operadores sociais e do direito devem buscar a colocação da criança em família substituta na forma de guarda, tutela ou adoção ou, ainda, a colocação em acolhimento institucional. Para tanto, são necessárias políticas e programas que viabilizem essas colocações, e o acolhimento familiar conta então com base legal para sua execução.

No que tange às normativas internacionais ratificadas pelo Brasil que podem auxiliar a argumentação pelo acolhimento familiar como uma modalidade de proteção, podem ser citadas aquelas que foram desconstruindo paradigmas e concretizando discussões sobre a criança ou o adolescente como sujeito de direitos em condição peculiar de desenvolvimento. São exemplos: a Declaração sobre os Direitos da Criança (1959); o Pacto Internacional dos Direitos Civis e Políticos (1966); o Pacto de São José da Costa Rica (1969); o Protocolo Adicional à Convenção das Nações Unidas contra o Crime Organizado Transnacional Relativo à Prevenção, Repressão e Punição do Tráfico de Pessoas, em especial Mulheres e Crianças (ratificado pelo Brasil em 2004); e o Protocolo Facultativo à Convenção sobre os Direitos da Criança Referente à Venda de Crianças, à Prostituição Infantil e à Pornografia Infantil, ratificado pelo Brasil em 2004 (MDS \& SEDH, 2006). No entanto, deve-se destacar o papel preponderante da Convenção sobre os Direitos da Criança (ONU, 1989).

Essa convenção, em seu preâmbulo, define o direito da criança à proteção especial e acrescenta a esse outros direitos (de liberdade de opinião, expressão, pensamento, religião etc), que demarcam duas prerrogativas que a sociedade e o Estado devem possibilitar à criança e ao adolescente, para operacionalizar a proteção dos seus Direitos Humanos: cuidados e responsabilidades. A discussão de medidas de acolhimento e proteção relaciona-se, então, aos cuidados que o Estado e a sociedade devem ter com a infância e juventude do país.

Dessa forma, é possível perceber que o acolhimento familiar vem sendo compreendido como uma medida de proteção a crianças e adolescentes que vivem situações de violação de direitos. Entretanto, ele abre questões que ainda demandam aprofundamento, discussão e adequação à nossa realidade cultural. Uma delas diz respeito a um dos aspectos desenvolvimentais da criança e do adolescente acolhido: a construção de vínculos e relações afetivas na família acolhedora. Outra se refere à transformação de uma cultura de acolhimento na sociedade, que comporte o acolhimento familiar, com novas significações de família, maternidade, paternidade. Conforme Cabral (2004) argumenta, o acolhimento familiar como programa alternativo à instituição merece mais estudo e aprofundamento teórico-prático, pois existe pouco conhecimento técnico sobre o tema. Para a autora, a implantação do acolhimento familiar "não significa puramente a transposição de um modelo de atendimento para o outro, como se o Acolhimento Familiar fosse uma 'solução' para substituir o estado atual das coisas" (p. 12).

Além disso, alguns problemas se configuram como fundamentais para serem analisados quando se pensa na constituição, fomento e sistematização de programas de acolhimento familiar. Por exemplo: Como eles estão se estruturando? Quais crianças visam atender (vitimizadas, grupo de irmãos, bebês, adolescentes, etc)? Que tipo de suporte especializado vão poder oferecer às famílias acolhedoras, às famílias de origem e aos acolhidos? Pode-se ainda perguntar se essa será uma alternativa de proteção adequada para crianças em todas as faixas etárias. Essas são questões que se levantam num momento de transição e de criação de uma nova cultura de acolhimento, que objetiva contemplar outros modelos de proteção diferenciados da antiga institucionalização. Questões que estão intimamente relacionadas às concepções de família, de acolhimento, de desenvolvimento da criança e do adolescente, de vínculo afetivo, que os projetos esposam.

\section{Perspectivas Teóricas de Vinculação Afetiva em Situações de Acolhimento}

A fundamentação teórica, na qual o ECA (1990) e os programas de acolhimento familiar já implantados no Brasil baseiam-se para valorizar a família como contexto primordial de desenvolvimento da criança, articula-se a algumas teorias dentro da Psicologia, especialmente a Psicologia 
do Desenvolvimento. A própria inclusão do direito à convivência familiar e comunitária nas normativas internacionais e nacionais foi subsidiada por teorias que ressaltavam a importância dos vínculos afetivos com as figuras parentais para o desenvolvimento saudável da criança, como também os efeitos nocivos ao desenvolvimento causado pelo processo de institucionalização.

Dessa forma, segundo Vicente (1998), o vínculo afetivo passou a ser valorizado nesses documentos e adquiriu uma dimensão política, visto que seu desenvolvimento e manutenção, quando não ocorre na família de origem, necessita de proteção do Estado, no sentido de assegurar essa possibilidade às crianças e adolescentes. Assim, o direito à convivência familiar passa a fazer parte de um conjunto de elementos das políticas públicas e fundamenta ações de colocação em famílias substitutas (sob guarda, tutela ou adoção) ou acolhedoras. Tais questões nos levam a refletir sobre os aportes teóricos, especialmente da Psicologia, em que se baseiam as práticas e políticas de acolhimento e assistência às crianças e adolescentes sob violação de direitos.

Das teorias que discutem a importância do estabelecimento de vínculos afetivos entre a criança e figuras parentais, destaca-se a Teoria do Apego, desenvolvida por Bowlby (1969/1990, 1952/1995, 1979/1997) e Ainsworth, Blehar, Waters e Wall (1978). Segundo ela, o ser humano é portador de uma história filogenética que lhe garante um aparato biológico, que o auxilia no estabelecimento e manutenção de vínculos afetivos com o outro, principalmente com a mãe (biológica ou substituta), sendo a constância dessa primeira vinculação afetiva crucial ao seu desenvolvimento psicossocial saudável. Nessa teoria, verificam-se concepções sobre a importância da constância de uma pessoa (geralmente associada à figura materna) no cuidado dispensado ao bebê e sobre a determinação de um período sensível para o desenvolvimento do apego, que seria dos seis primeiros meses de vida aos três anos de idade. Assim, os autores tratam da primazia da relação de apego mãe-criança, apontando para conseqüências disfuncionais sobre o desenvolvimento social, psicológico e emocional da criança, caso a relação não se estabeleça, seja interrompida ou se mantenha de modo inadequado (RossettiFerreira, 1986, 2006).

Bowlby é bastante citado na escassa literatura nacional sobre acolhimento familiar. A sua visão de que a institucionalização, o rompimento de vínculos e a privação materna deixariam marcas profundas e prejudiciais na criança é freqüentemente usada na argumentação para criação de programas de acolhimento familiar como alternativa ao acolhimento em instituições:

O fracasso no desenvolvimento da personalidade nas crianças que sofreram privação é, talvez, melhor compreendido quando se considera que é a mãe que, nos primeiros anos de vida da criança, funciona como sua personalidade e consciência. A criança em instituição nunca teve estas experiências, dessa forma, não pode nunca completar a primeira fase do desenvolvimento estabelecer uma relação com uma figura materna clara- mente definida. Tudo que teve foi uma sucessão de agentes paliativos, cada um auxiliando-a de uma forma limitada, mas nenhum deles proporcionando-lhe a continuidade no tempo, que faz parte da essência da personalidade. É bem possível que essas crianças, gravemente privadas por nunca terem sido objeto de um cuidado por parte de um mesmo ser humano, nunca tenham tido a oportunidade de aprender os processos de abstração e de organização do comportamento no tempo e no espaço. Certamente, suas graves deformações psíquicas são exemplos claros do princípio de que os danos infligidos muito cedo produzem perturbações generalizadas no crescimento (Bowlby, 1952/ 1995, p. 61).

Nesse trecho é evidente a argumentação de que a privação materna favoreceria a origem de uma psicopatologia, o que, para o autor, estaria associada à vivência institucional. Bowlby (1979/1997) considerava que muitos distúrbios psiconeuróticos e da personalidade eram reflexos de distúrbios na capacidade de estabelecimento de vínculos afetivos, originados numa "falha" de desenvolvimento na infância ou em transtornos posteriores. Em seus escritos cita várias pesquisas realizadas na década de 60 que tinham esse enfoque e que traduziam uma concepção quase hegemônica na ciência psiquiátrica e psicológica de associarem a psicopatia, sociopatia, depressão e a delinqüência com a privação materna, paterna ou orfandade. Rutter (1972) teceu críticas bem fundamentadas sobre esses estudos, que observavam comportamentos de pacientes psiquiátricos ou crianças institucionalizadas, apontando que as patologias presentes derivavam mais das péssimas condições institucionais a que eles foram submetidos do que propriamente à privação materna.

Outro aspecto a se considerar é que tal concepção sobre o desenvolvimento humano coloca o contexto familiar como o locus privilegiado para o estabelecimento das relações de apego, contexto em que a criança teria um cuidador individualizado. Também apresenta uma tendência à patologização de contextos coletivos de desenvolvimento da criança (como os abrigos), especialmente para a criança pequena. Nesse caso, pouco valor é dado para o estabelecimento de vínculos afetivos com outros cuidadores que não a mãe ou substituta, ou mesmo, com coetâneos. Essa visão de estabelecimento de apego centra-se na análise de relações diádicas, pouco considerando o dinamismo das relações familiares, os outros interatores, as significações e práticas presentes nesse contexto, que são marcados pela cultura em que se inserem (Rossetti-Ferreira, 2006).

A supremacia dos laços consangüíneos para o cuidado de crianças é, sem dúvida, uma ideologia dominante em nossa sociedade. Em parte, é dessa idéia que emana a concepção hegemônica encontrada em diversas tendências teóricas da predestinação à psicopatologia das crianças separadas da família biológica. Seus históricos de vida, às vezes marcados por aquilo que a literatura clássica de desenvolvimento humano considera estressores sociais de diversas ordens, aos quais se somam vivências institucionais, são vistos a partir de 
uma conotação negativa, idéia predominante que se espraia em diferentes âmbitos da vida social, permeando tanto os discursos do senso comum como os do meio científico (Rossetti-Ferreira, 2006).

Dessa forma, a ameaça ou existência de rupturas afetivas anteriores parece criar enredamentos ou tramas que as pessoas em interação reeditam nas suas práticas dialógicas e discursivas, co-construindo no momento atual, os problemas ou uma visão de desenvolvimento inadequado para essas crianças. Rossetti-Ferreira (2007) argumenta que a Teoria do Apego constitui um exemplo da relevância das ciências do desenvolvimento humano para a definição das políticas e práticas sociais de educação e proteção de crianças e jovens, sobretudo daqueles que vivem situações de vulnerabilidade social. Isso porque as redes de significações que permeiam as políticas e práticas de acolhimento de crianças e adolescentes historicamente esbarram em certas idéias predominantes sobre apego, desenvolvimento normal/anormal, fatores de risco/fatores protetores e sobre a concepção de que a instituição familiar, particularmente a do tipo nuclear, é a única e a ideal, aquela que melhor oferece um ambiente pleno ao desenvolvimento de uma criança. Assim, as visões teórico-metodológicas da área contribuem para construir realidades sociais que podem influir, modificar e restringir o desenvolvimento e a qualidade de vida das pessoas, muitas vezes inserindo-as em um movimento de exclusão.

Cabral (2004), ao defender a criação dos programas de acolhimento familiar, retoma a questão da construção de vínculos afetivos como um dos seus argumentos centrais. Afirma que o acolhimento em famílias garante o direito a uma convivência familiar com dignidade e a possibilidade de construção de laços afetivos. Entretanto, temos nos perguntado como seria essa "propagandeada" construção de vínculos dentro de um programa de acolhimento familiar, visto ser esperado que eles sejam estabelecidos, porém com um caráter de provisoriedade, pois todos os envolvidos devem saber que haverá o momento de nova separação, quando o acolhido retornará à sua família de origem ou será colocado em adoção. Como os programas estão concebendo a possibilidade da criança ou adolescente vincular-se a uma ou mais famílias de acolhimento e depois retornar para a família de origem? E, ainda, como manter o vínculo com a família de origem?

Essas são questões complexas, que instigam a condução de pesquisas, entretanto, consideramos necessário que seja assumido outro paradigma para compreensão da construção de vínculos afetivos, dentro de uma perspectiva contextual e sistêmica que possa abordar a complexidade do assunto. É interessante considerar as idéias de Lewis (1999), quando ele argumenta que a múltipla determinação, acasos, os encontros acidentais e a interação desses, são problemas inerentes ao desenvolvimento humano e que dificultam a previsão do curso da vida humana. $\mathrm{O}$ autor critica idéias das teorias do desenvolvimento, que ele chama de "idéias fixas", as quais são inquestionavelmente aceitas, como: a perspectiva de continuidade e evolução no desenvolvimento, a causalidade no passado e a idéia de que o passado atua sobre o presente e o futuro. Tudo isso compõe o que ele chama de um modelo organicista de desenvolvimento, que sempre considera a criança no processo de vir-a-ser, no que ela se tornará no futuro, e, sobre o qual, a maioria das políticas públicas de atenção à infância e juventude se baseia. Para o autor, é necessário intervir quando se presencia sofrimento e injustiça, mas fazer isso buscando alcançar um efeito no futuro "pode ser uma bobagem, porque nós e as forças sobre as quais não temos controle - alteramos nossos destinos todos os dias, de forma imprevisível" (Lewis, 1999, p. 31).

Lewis (1999) propõe um modelo contextual de desenvolvimento que considere a natureza do ambiente onde a criança cresce, o "comportamento-em-contexto," a rede social em que se insere, inclusive para se falar em desenvolvimento afetivo. Argumenta que as políticas sociais devem considerar o momento presente da família, o momento do acolhimento, e que a idéia do curar deve dar lugar à idéia do cuidar, numa alusão às teorias organicistas que estão sempre amarradas ao passado, preocupadas com o futuro e com a cura.

Em consonância com essas idéias, consideramos que para se compreender o desenvolvimento afetivo e o apego é necessário desfocar das relações diádicas e buscar apreender a rede de relações (e significações) em que a criança está imersa, a partir de uma perspectiva processual, relacional, situada e discursiva. Entendemos que o apego é construído nas e através das interações e relações recíprocas, que ocorrem em contextos específicos. Tais contextos envolvem discursos vivenciados e situados, os quais colocam os parceiros em certas posições. Esse processo favorece a construção de certos sentidos e um repertório de papéis possíveis, circunscrevendo (estabelecendo limites e possibilidades para) assim o fluxo de comportamentos e o desenvolvimento dos sujeitos (Rossetti-Ferreira, 2007).

Gailey (2000), ao abordar a realidade social norte-americana, discute que a adoção e o acolhimento familiar constituem um desafio à noção de que a maternidade, a paternidade e a possibilidade de vinculação afetiva das crianças estão associadas a conexões genéticas ou de nascimento. Segundo a autora, eles fornecem uma lente através da qual podem ser vistos os vínculos de afetividade e parentesco sendo construídos.

Tal discussão nos leva a considerar que a compreensão de como as equipes dos programas de acolhimento familiar estão significando o processo de vinculação afetiva daqueles envolvidos no acolhimento (acolhidos, família acolhedora e família de origem) é de grande importância para o desenvolvimento dos projetos, conforme afirma o Plano Nacional.

A decisão sobre a separação é de grande responsabilidade e deve estar baseada em uma recomendação técnica, a partir de um estudo diagnóstico, caso a caso, realizado por equipe interdisciplinar, com a devida fundamentação teórica - desenvolvimento infantil, etapas do ciclo de vida individual e familiar, teoria dos vínculos e estratégias de sobrevivência de famílias em situação de extrema vulnerabilidade. A realização deste 
estudo diagnóstico deve ser realizada em estreita articulação com a Justiça da Infância e da Juventude e o Ministério Público, de forma a subsidiar tal decisão (MDS \& SEDH, 2006, p. 71, grifos nossos).

\section{Considerações Finais}

Ao refletir sobre o acolhimento familiar como mais uma alternativa de proteção e acolhimento para crianças e adolescentes em situação de vulnerabilidade e violação de direitos, necessariamente discutimos mudanças de concepções de infância e juventude, do papel da família, das perspectivas sobre construção de vinculação afetiva e desenvolvimento infantil. Entendemos que ao fomentar uma nova cultura de acolhimento, necessária num momento de desinstitucionalização e reordenamento das políticas de proteção social, isso comporta outras significações de família, vinculação, maternidade e paternidade. Vale refletir que convivemos na atualidade com diversos arranjos familiares. Observam-se, no campo das relações familiares famílias monoparentais, nucleares, recompostas, ampliadas, famílias formadas por casais homossexuais, coexistindo em uma mesma sociedade e tempo histórico. Essas transformações sociais têm uma relação dialógica com a ressignificação e produção de novos sentidos de maternidade e paternidade, como também de acolhimento de crianças e adolescentes na família, sem serem necessariamente filhos biológicos. Atualmente, as famílias (recompostas, ampliadas, etc.) comportam o desejo ou a obrigatoriedade de conviver com novas realidades, com o diferente, a alteridade.

Para Fonseca (2004), considerar a família de acolhimento como complementar à família de origem é algo novo no Brasil. A autora argumenta que, embora o ECA fale de famílias substitutas, ele prioriza a atenção para um tipo particular de família substituta: a família adotiva. Também as instituições de abrigamento, habitualmente, têm visado a colocação de crianças e adolescentes em famílias substitutas adotivas em detrimento de abordagens que favoreçam a reintegração familiar, embora esse trabalho lhe seja especificamente atribuído pelo ECA.

Assim, mudar uma cultura de acolhimento que tem raízes históricas na institucionalização de crianças e criar novas medidas de proteção (dentre elas, o acolhimento familiar) não é um processo rápido. É inegável que existem tensões entre a adoção de um novo discurso social (que promove acolhimento familiar e alternativas de permanência da criança e adolescente em sua família de origem) e práticas culturais antigas de internação, marcadas pelo estigma de que as famílias cujas crianças e adolescentes precisam de acolhimento são incompetentes e, por isso, precisam ser afastadas da convivência (Rizzini, Rizzini, Naiff, \& Baptista, 2007).

Entretanto, vivemos no Brasil o momento de repensar essas práticas, para que o direito das crianças e adolescentes à convivência familiar e comunitária não fique apenas no papel, como uma carta de intenções. Dessa forma, uma nova cultura de acolhimento deve considerar, elaborar e implementar um leque de opções de acolhimento (aco- lhimento familiar, pequenos abrigos com atendimento de qualidade, casas-lares, repúblicas, famílias adotivas) que possam ser utilizadas, a depender dos diversos fatores que envolvem a criança ou adolescente em foco, como o contexto social, a problemática familiar, a idade, suas condições de saúde, a presença ou não de irmãos, etc. Parece ser necessário romper com a dicotomia instaurada entre formas de acolhimento, em que se busca a defesa de uma como melhor, única e mais adequada, em detrimento de outras. O momento é de assumir que para trabalhar com uma realidade complexa precisamos de diversas formas de acolhimento, desde que todas sejam desempenhadas com qualidade e compromisso, o que envolve qualidade de ambientes, de pessoal, de capacitação inicial e em serviço, de conhecimentos técnicos, etc.

Nesse momento de mudança, é desafiante investigar as transformações nas práticas de acolhimento à infância e juventude, questões que merecem a nossa atenção, no sentido de auxiliar o trabalho daqueles que vêm atuando no campo. Concordamos com Souza (1994) quando ele afirmava que em resposta a uma ética da exclusão, a sociedade brasileira e cada cidadão em específico estão desafiados a praticar uma ética da solidariedade, que exigirá novos paradigmas de compreensão dos nossos problemas sociais e soluções plurais e criativas.

\section{Referências}

Ainsworth, M. D. S, Blehar, M., Waters, E., \& Wall, S. (1978). Patterns of attachment: A psychological study of the strange situation. Hillsdale, NJ: Erbaum.

Amorós, P., \& Palacios, J. (2004). Acogimiento familiar. Madrid, España: Alianza.

Amorós, P., Palacios, J., Fuentes, N., \& Léon, E. (2003). Familias canguro. Una experiencia de protección a la infancia. Sevilla, España: Fundación "la Caixa".

Amorós, P., \& Peláez, N. F. (2004). Perspectivas y tendencias del acogimiento familiar en Cataluña. In D. Marre \& J. Bestard (Eds.), La adopción y el acogimiento. Presente y perspectivas (pp. 173-194). Barcelona, España: Ediciones de la Universitat de Barcelona.

Baptista, M. V. (2006). Um olhar para a história. In M. V. Baptista (Ed.), Abrigo: Comunidade de acolhida e socioeducação (pp. 25-36). São Paulo, SP: Instituto Camargo Correia.

Brasil, E. D. (2004). O conceito de acolhimento familiar na ótica dos vários atores estratégicos. In C. Cabral (Ed.), Colóquio internacional sobre acolhimento familiar (pp. 102-111). Rio de Janeiro, RJ: Terra dos Homens.

Bowlby, J. (1990). Apego (A. Cabral, Trad.). São Paulo, SP: Martins Fontes. (Original publicado em 1969)

Bowlby, J. (1995). Cuidados maternos e saúde mental (V. L. B. de Souza \& I. Rizzini, Trads.). São Paulo, SP: Martins Fontes. (Original publicado em 1952)

Bowlby, J. (1997). Formação e rompimento de laços afetivos (A. Cabral, Trad.). São Paulo, SP: Martins Fontes. (Original publicado em 1979)

Cabral, C. (2004). Perspectivas do acolhimento familiar no Brasil. In C. Cabral (Ed.) Acolhimento familiar. Experiências e perspectivas (pp. 10-17). Rio de Janeiro, RJ: UNICEF.

Constituição da República Federativa do Brasil. (1988). Brasília, DF: Senado Federal. 
Del Valle, J. F., \& Arteaga, A. B. (2003). Situación actual del acogimiento familiar de menores en Espana. Oviedo, España: Ministerio de Trabajo y Asuntos Sociales.

Estatuto da Criança e do Adolescente. (1990, 16 jul.). Lei $\mathrm{n}^{\circ}$ 8.069, de 13.06.1990. Diário Oficial da União, Brasília, DF.

Fávero, E. T. (1995). Serviço Social - Práticas judiciárias e poder. Dissertação de Mestrado não-publicada, Faculdade de Serviço Social, Pontifícia Universidade Católica de São Paulo, SP.

Fernández, J., Álvarez, E., \& Bravo, A. (2003). Evaluación de resultados a largo plazo en acogimiento residencial de protección a la infancia. Infancia y Aprendizaje, 26, 235-249.

Fonseca, C. (1995). Caminhos da adoção. São Paulo, SP: Cortez.

Fonseca, C. (2004). Fabricando família: Políticas públicas para o atendimento de jovens em situação de risco. In C. Cabral (Ed.), Acolhimento familiar. Experiências e perspectivas (pp. 86-101). Rio de Janeiro, RJ: UNICEF.

França, M. (2006). Famílias acolhedoras. Preservando a convivência familiar e comunitária. São Paulo, SP: Veras.

Franco, A. A. P. (2000). Sobre silêncios e palavras: Os lugares da infância e da juventude. O trabalho desenvolvido com famílias substitutas na Comarca de Franca-SP. Dissertação de Mestrado não-publicada, Faculdade de Serviço Social, Universidade Estadual Paulista, Franca, SP.

Gailey, C. W. (2000). Ideologies of motherhood and kinship in US adoption. In H. Ragoné \& F. Twine (Eds.), Ideologies of motherhood (pp. 11-55). New York: Routledge.

George, S., \& Van Oudenhoven, N. (2003). Apostando al acogimiento familiar - un estudio comparativo internacional (M. Soledad Franco, Trans.). Amberes, Bélgica: International Foster Care Organisation.

Instituto de Pesquisa Econômica Aplicada. (2003). Levantamento Nacional dos Abrigos para Crianças e Adolescentes da Rede de Serviço de Ação Continuada (SAC) (Relatório de Pesquisa No. 1). Brasília, DF: Autor.

Justo, J. S. (1997). A institucionalização vivida pela criança de orfanato. In A. J. Merisse, J. S. Justo, \& L. C. Rocha (Eds.), Lugares da infância: Reflexões sobre a história da criança na fábrica, creche e orfanato (pp. 71-91). São Paulo, SP: Arte e Ciência.

Lewis, M. (1999). Alterando o destino: Por que o passado não prediz o futuro. São Paulo, SP: Moderna.

Lei Orgânica da Assistência Social. (1993). Lei no. 8.742, de 07.12.1993. Diário Oficial da União, Brasília, DF.

Luna, M. (2004). Algumas definições sobre acolhimento familiar e seu desenvolvimento na Argentina. In C. Cabral (Ed.) Acolhimento familiar. Experiências e perspectivas (pp. 112121). Rio de Janeiro, RJ: UNICEF.

Ministério do Desenvolvimento Social. (2004). Política Nacional de Assistencia Social. Brasília, DF: Autor.

Ministério do Desenvolvimento Social \& Secretaria Especial de Direitos Humanos (2006). Plano Nacional de Promoção, Proteção e Defesa do Direito de Crianças e Adolescentes à Convivência Familiar e Comunitária. Brasília, DF: Autores.

Organização das Nações Unidas. (1989). Convenção sobre os Direitos da Criança. New York: Autor.

Palacios, J., \& Amorós, P. (2006). Recent changes in adoption and fostering in Spain. British Journal of Social Work, 17, $1-15$.

Rizzini, I. (1993). Assistência à infância no Brasil. Uma análise de sua construção. Rio de Janeiro, RJ: Editora Universitária Santa Úrsula.
Rizzini, I., \& Rizzini, I. (2004). A institucionalização de crianças no Brasil: Percurso histórico e desafios do presente. Rio de Janeiro, RJ: Editora da Pontifícia Universidade Católica do Rio de Janeiro.

Rizzini, I., Rizzini, I., Naiff, L., \& Baptista, R. (2007). Acolhendo crianças e adolescentes. São Paulo, SP: Cortez.

Rossetti-Ferreira, M. C. (1986). Mãe-criança: Separação e reencontro. São Paulo, SP: Edicon.

Rossetti-Ferreira, M. C. (2006). Olhando a pessoa e seus outros, de perto e de longe, no antes, aqui e depois. In D. Colinvaux, L. Banks, \& D. D. Dell'Aglio (Eds.), Psicologia e desenvolvimento: Reflexões e práticas atuais (pp. 19-59). São Paulo, SP: Casa do Psicólogo.

Rossetti-Ferreira, M. C. (2007). Significação e dialogia na perspectiva da Rede de Significações (Relatório Temático Fapesp No. 4). Ribeirão Preto, SP: FAPESP.

Rutter, M. (1972). Maternal deprivation reassessed. London: Penguin Books.

Sarti, C. A. (1996). A família como espelho. Campinas, SP: Autores Associados.

Silva, E. R. (2004). O direito a convivência familiar e comunitária: Os abrigos para crianças e adolescentes no Brasil. Brasília, DF: IPEA.

Souza, H. J. (1994). A cura da Aids. Rio de Janeiro, RJ: RelumeDumará.

Uriarte Bálsamo, P. (2005). Substituindo famílias: Continuidades e rupturas na prática de acolhimento familiar intermediada pelo estado em Porto Alegre, 1946/2003. Dissertação de Mestrado não-publicada, Instituto de Filosofia e Ciências Humanas, Universidade Federal do Rio Grande do Sul, Porto Alegre, RS.

Vicente, C. M. (1998). O direito a convivência familiar e comunitária: Uma política de manutenção do vínculo. In S. M. Kaloustian (Ed.), Família brasileira: A base de tudo (pp. 4759). São Paulo, SP: Cortez. 